\title{
A Formação Militar-Naval Brasil-Argentina no Contexto de Cooperação no Atlântico Sul: visões sobre a situação regional
}

The Naval Military Formation-Brazil-Argentina in the Context of Cooperation in the South Atlantic: views on regional situation

Resumo: O texto é uma apresentação de como o relacionamento entre o Brasil e a Argentina nas últimas cinco décadas, afetou a percepção e a constituição político-estratégica das Marinas de ambos os países. De uma postura de rivalidades e competição, passaram para as tentativas de integração e cooperação em vários setores, inclusive o militar-naval. Neste sentido, considera certos temas significativos na implementação do Mercosul e das medidas de confiança mútua junto com outros vizinhos do subcontinente sul-americano, a partir da perspectiva de analistas e civis e oficiais-marinheiros brasileiros e argentinos ao justificarem os avanços e limites da cooperação. E assim, leva em conta o estabelecimento das bases da política de defesa e algumas consequências para a formação militar-naval nos dois países.

Palavras-chave: Cooperação Regional; Pensamento Político-estratégico; Armada Argentina; Marinha do Brasil.

Abstract: The text is a presentation of how the relationship between Brazil and Argentina in the last five decades has affected the perception and constitution of the political-strategic Marinas in both countries. From a position of rivalry and competition, they opted to the attempts of integration and cooperation in various sectors, including the military-naval one. In this sense, certain significant issues are considered in the implementation of the Mercosur and of confidence-building measures along with other neighbors in the South American subcontinent, from the perspective of analysts, civilians and Brazilian and Argentinian official mariners justifying the advances and limits of the cooperation. And so, It is taken into account the establishment of the defense policy bases and some consequences for the military-naval formation in both countries.

Keywords: Regional Cooperation; Political and Strategic Thought; The Argentinian Navy; Brazilian Navy.

\section{Introdução}

Este texto é uma parte integrante da pesquisa de pós-doutorado realizada no CELA-GEDESUNESP-Franca realizada entre 2003 e 2005, intitulada A Formação Militar-Naval Brasil Argentina no Contexto de Cooperação no Atlântico Sul (SILVEIRA, 2005). A primeira versão do texto foi apresentada na III Congresso Latino-americano de Ciência Política (ALACIP), realizado na UNICAMP, de 4 a 6 de Setembro de 2006. Aqui, apresentamos os pontos que consideramos significativos para tratar da situação do Mercosul e o pensamento político-estratégico expresso no âmbito naval brasileiro e argentino, por militares e civis que se debruçaram sobre o tema da

\footnotetext{
- Professor Doutor - Departamento de Ciências Sociais, Departamento de Educação e do Programa de Pós-Graduação em Relações Internacionais - Instituto de Filosofia e Ciências Humanas - Univ. Estadual do Rio de Janeiro - Rua São Francisco Xavier, 524, CEP: 20550-900, Rio de Janeiro, RJ, Brasil. Atualmente realiza outra pesquisa de pós-doutorado sobre a Política de Defesa e a Formação Militar-Naval do Brasil e da Espanha, no IUGM-UNED-Madri com apoio da CAPES. E-mail: ccsilv@yahoo.com
} 
cooperação regional nas últimas duas décadas. De modo mais específico, fazemos alusão aos argumentos de analistas políticos, acadêmicos e chefes militares-navais preocupados em debater sobre a região, buscando estabelecer algum rumo para o curso das relações entre esses dois países. Por fim, apresentamos algumas de nossas considerações à guisa de conclusão.

No primeiro momento, apresentaremos aqui os pressupostos teóricos adotados sobre o contexto regional de criação do Mercosul e a cooperação regional protagonizadas pelo Brasil e pela Argentina, com base na literatura acadêmica concernente à temática do nosso objeto de pesquisa. Em seguida, apresentaremos nossa perspectiva acerca da profissão militar latino-americana e as suas características existentes nos dois países, com as especificidades da carreira militar-naval, utilizando a contribuição de alguns analistas especializados neste assunto.

\section{O Brasil, a Argentina e o Mercosul}

Com a maior aproximação diplomática da República Federativa do Brasil e da República Argentina, a partir dos anos 1970, as relações político-estratégicas entre ambos alcançaram bom termo. Isto estabeleceu a cooperação científico-tecnológica, notadamente no campo nuclear, nas resoluções sobre as hidrelétricas de Itaipu e Corpus, na democratização destes países e na organização do Mercosul. O tema da cooperação bilateral Brasil-Argentina tem sido tratado comumente como um "desafio" em função das dificuldades naturais no entrosamento entre dois países e a sua situação no hemisfério. Neste sentido, não se pode esquecer da presença hegemônica dos EUA. Conforme alguns analistas, há uma "relação triangular" que não pode ser desprezada por ser considerada desigual em razão da projeção da superpotência no cenário mundial. Mas, um fator considerável é a existência de "desequilíbrios" e "disparidades" entre os países sul-americanos enquanto partes envolvidas (RUSSELL; TOKATLIAN, 2004).

A questão da cooperação entre Brasil e Argentina, tem se desenvolvido quando ambos os países passam por momentos diferentes na condução de suas Forças Armadas (FFAA), como o Brasil utilizando-as para debelar crises de segurança pública e mantendo prerrogativas autônomas, distintas de outras corporações estatais e a Argent. Mesmo assim, a conjugação dos interesses nacionais com os interesses regionais em comum vem a ser uma realidade entre esses países, que já experimentam um intercâmbio proveitoso na área de defesa. Por isso, o relacionamento brasoargentino pode, então, ser pensado como uma cooperação "estratégica", desfazendo temores e diminuindo a adesão direta aos EUA. Este contexto de cooperação também se refletiu ao longo da história, na maneira pela qual ambos os países encaminharam seu direcionamento para a formação e o treinamento militar entre si e na relação com aquele país (HAYES,1995). 
Tal fato não impediu que Brasil e Argentina pudessem construir um vínculo histórico proveitoso, mesmo com as oscilações argentinas diante dos EUA e as dificuldades no estabelecimento da interdependência entre brasileiros e argentinos nas últimas décadas do século passado, instituindo o Mercosul, além do seu desenvolvimento no século atual com a intenção de manter um padrão de associação entre ambos e da formação de consensos e declarações feitos entre os respectivos governos, como ocorreu no ano de 2004 em Buenos Aires e no Rio de Janeiro.

Cada vez mais se percebe que o governo brasileiro procurou estabelecer uma prioridade para o Mercosul na sua política externa. Na Argentina, isto é visto por alguns como a caracterização atual do "destino manifesto" de nosso país, como um instrumento de busca e afirmação de sua supremacia na região. Daí, aconteceram os esforços continuados dos governos de Fernando Henrique Cardoso e Luís Inácio Lula da Silva para a consolidação do bloco, a despeito das desavenças com os argentinos (MINISTERIO DE DEFENSA, 2003).

Entendemos que o arranjo mercosulino não prescinde das vontades individuais dos países. Por isso, podemos considerar que a soberania continua sendo importante, ao passo que os Estados abrem mão de uma parcela de sua autonomia em nome de uma entidade coletiva. Tal fato passa a constituir uma relação de interdependência (KEOHANE, 1995) entre eles que pode continuar ou não, de acordo com suas próprias combinações políticas e trabalharem no sentido da cooperação, apesar da existência de conflitos (NYE, 1990).

Neste sentido, conforme Barnabé (2003) e Vaz (2002) admitimos que a regionalização pode coexistir ao lado da condição de desenvolvimento social e dos objetivos políticos internos e externos de cada país, pois eles continuam determinando as suas formas de relacionamento com os outros, tal qual é o caso da cooperação regional mercosulina. Neste caso, a vontade política poderá prevalecer a despeito das contendas econômicas, facilitando a organização de uma estratégia de cooperação em várias áreas, assim como no campo da segurança internacional e da defesa. As estruturas militares e os projetos de forças oriundos dos planejamentos das políticas de defesa poderão existir de acordo com as características nacionais. Porém, como já foi assinalado, apesar das atitudes de maior aproximação entre o Brasil e a Argentina, não experimentamos uma plena integração no campo militar porque ambos os países mantêm a sua soberania, sem resolver abrir mão delas, como é comum nas relações internacionais (MIYAMOTO, 1997).

Como já foi mencionado anteriormente, a relação bilateral entre esses dois países se insere no contexto hemisférico. No que tange às questões de segurança regional, lembra Rosendo Fraga o incremento da relação das FFAA latino-americanas com os EUA por meio das conferências dos ministros da defesa, desde Wiliamsburg de 1995 se discute maior articulação entre os países. Contudo, houve questões a considerar, tais como as distinções e peculiaridades das relações civis- 
militares nos países americanos, as diferentes competências dos respectivos ministérios, a situação do TIAR e o futuro da OEA, as expectativas sobre tal tipo de encontro, que podem ser, às vezes, exageradas (FRAGA, 1997).

Nesse contexto, assim mesmo a educação profissional das FFAA passou a ser pautada por medidas de confiança mútua entre eles com alteração do cenário regional, onde a realidade anterior de rivalidades deu maior lugar à cooperação, ainda que para alguns permaneçam certos temores e críticas sobre as intenções brasileiras (MIYAMOTO, 2003). Porém, na formação dos militares para o cumprimento de suas missões das FFAA existem as pressões dos EUA para os militares latinoamericanos combaterem o narcotráfico e comprarem mais de suas armas e equipamentos militares, embora a região não seja uma prioridade para este país. Na realidade argentina os militares não lutam contra as drogas, a não ser no campo da inteligência eterna, no controle do espaço aéreo e no apoio logístico às polícias (no Brasil as atribuições são semelhantes; até mesmo as FFAA rejeitam que haja modificações desta situação).

Por isso, é mais importante avaliar como a cooperação regional é significativa na relação do Brasil com a Argentina, no campo naval (que remonta aos governos de Frondizi e Kubischek, dando continuidade ao longo dos presidentes militares após a diminuição das rivalidades entre ambos). Assim como as operações UNITAS, as operações FRATERNO estimulam maior intercâmbio e aperfeiçoamento das Forças Navais da região mercosulina para além das questões comerciais. Entre a Armada da República Argentina (ARA) e a Marinha do Brasil (MB) os primeiros passos foram dados e são bastante significativos para consolidar essa atitude cooperativa no mar e o aumento do diálogo e ampliar a visão comum de estratégia dissuasiva. De todo modo, persistem diferenças de organização burocrático-institucional das FFAA e das alianças com outros países (como os EUA e a vinculação extra-OTAN) e as intenções brasileiras de pertencer ao Conselho de Segurança da ONU, as quais a Argentina apresentaram restrições importantes. As diferenças entre Brasília e Buenos Aires persistem como as tensões em relação ao Mercosul, mas a realidade pode apresentar soluções factíveis, segundo as vontades dos governos para ampliar a cooperação binacional. Concordamos com alguns analistas: na implementação do projeto mercosulino existem outras dificuldades desde a sua criação, causando implicações na dimensão educacional. Não foi feito um consistente cronograma de implementação e não há uma preocupação mais abrangente sobre a configuração de uma agenda na área de segurança e defesa e o preparo e emprego das FFAA, conforme argumentaram Saint-Pierre e Mathias (1997).

Eles advogam a importância de se pensar uma cooperação militar que vá além das parcerias, que levem a uma atitude de maior integração: concepção estratégica unificada e constituição de uma força tarefa comum, acompanhada de um conjunto de procedimentos capaz de efetivá-los, como o 
estímulo a exercícios e cursos comuns, a reformulação da ideologia e o preparo dos militares, a formação de um corpo de tarefas operacionais de rápido emprego para garantir dos interesses regionais e a elaboração de planos de defesa comuns.

\section{A Formação Militar Naval e a Cooperação Regional}

A questão da cooperação entre as Marinhas da região pode ser tratada através do conceito de Medidas de Confiança Mútua (MCM), como o capitão-de-mar-e-guerra Luis C. de C. Roth,(2002) ao tratar numa monografia do Curso de Política e Estratégias Marítimas (C-PEM), da Escola de Guerra Naval (EGN) das medidas de Confiança Mútua (MCM), com especificidade para as MCM marítimas que se desenvolveram a partir dos anos 80 e 90 no âmbito do Mercosul original e da sua versão ampliada, com a participação de outros Estados do subcontinente, e que contempla a participação de organismos como o TIAR, a JID e a OEA. Houve uma série de eventos anteriores e posteriores que materializaram as boas intenções entre Brasil e Argentina, além de demais países da região. Esses eventos puderam propiciar um diálogo maior entre os países para tratar dos temas de comunicação, restrição, transparência e verificação entre os mesmos, por exemplo, o estabelecimento do Tratado de Tlatelolco de 1967, da ZPCAS de 1986, da Declaração Política do Mercosul de 1998, da Declaração de São Salvador, 1998, da Assembleia da OEA de Santiago em1991, da Reunião de Peritos, ocorrida em Buenos Aires de 1994, das reuniões específicas sobre MCM em Santiago 1995. Não podemos descartar também a assinatura do Tratado de NãoProliferação de Armas Nucleares, assinado pelo Brasil.

A valorização da cooperação entre o Brasil e seus vizinhos tem sido alvo da formação político-estratégica dos oficiais brasileiros. As MCM são justificadas em função da influência do mar na vida profissional marinheira, do emprego político do poder naval, da tradição histórica de tratados e acordos, além de códigos e convenções do uso do mar, do trânsito de embarcações de guerra nos oceanos, no foco de disputas centrado em terra, no aproveitamento econômico da área marítima e da indivisibilidade do mar. Os temas a estes fatores relacionados são o controle de armamento naval, a prevenção de incidentes no mar, as reuniões de oficiais de altas patentes, as viagens e visitas e cursos para os oficiais, a cooperação naval em diversas áreas, a busca e salvamento, os exercícios navais conjuntos, segurança operacional, controle da área marítima, transporte marítimo, cooperação em patrulha naval, meio ambiente marinho, exercícios de operação de paz, construção e reparo naval.

A história da cooperação entre as Marinhas brasileira e argentina, se inscrevem nas atividades das operações UNITAS da década de 60, da formação do Controle da Área Marítima do Atlântico Sul (CAMAS) estabelecido em 1967 (juntamente com o Uruguai e o Paraguai) e das operações 
ATLANTIS criadas em 1968, ainda num clima de manutenção de rivalidades entre os dois países. Neste sentido, ressalta-se o pioneirismo das duas Marinhas, pois somente a partir do Acordo de Itaipu em 1979, que estabeleceu a cooperação tripartite entre Brasil, Argentina e Paraguai, é que as tensões diminuíram. Isso possibilitou ainda a cooperação no campo nuclear e o apoio brasileiro ao país platino, por ocasião da Guerra das Malvinas. Decerto que o Tratado de Assunção, de 1991, que instituiu o Mercosul, assim como o Acordo Bilateral sobre Energia Nuclear consolidaram as expectativas de maior cooperação entre os dois países. Na década de 70 as operações FRATERNO foram implementadas, retomando a tradição interrompida das operações ATLANTIS e ARAEX, feitas em 1992 no âmbito da aviação com o uso de seus navios-aeródromo, consagrando o maior aprofundamento entre as duas Marinhas. As expedições brasileiras à Antártida também estão no campo da cooperação com a Argentina e com o Chile, para o estabelecimento da Estação Antártica Comandante Ferraz em 1983, apesar das divergências com o Brasil, que revela mais apreço pela tese internacionalista, e os seus dois vizinhos austrais, que advogam a tese territorialista para o uso da Antártida. Outras divergências entre os dois maiores países do subcontinente continuam, tais como: a aliança extra-OTAN, firmada pela Argentina e a busca do Brasil por um assento permanente no Conselho de Segurança da ONU. Entretanto, as divergências políticas não são empecilho para que haja um grande intercâmbio na formação e treinamento entre os oficiais das duas corporações. Tal fato pode ser demonstrado nos estágios de aspirantes de ambas as escolas navais e na presença dos oficiais brasileiros e argentinos nos cursos de estado-maior das suas escolas de guerra naval. No treinamento operacional, destaca-se a famosa troca de competências com o reparo em embarcações como o submarino argentino Santa Fé feita pela MB no Rio de Janeiro, e a revisão das caldeiras das fragatas brasileiras da classe Greenhalg, feita pela ARA na Argentina.

A inserção regional do Brasil dentro de um quadro de projeção geopolítica também foi abordada no C-PEM pelo capitão-de-mar-e-guerra Joaquim A. B. Rego (2003), como se vê na literatura militar-naval sobre o tema da relação entre os países da América do Sul. Valorizando a produção nacional sobre o tema, ainda que contando com os clássicos e a produção contemporânea sobre a geopolítica. O Brasil é entendido como um "ator global” que está limitado pelos países da tríade a qual controla o processo global, capitaneada pelos EUA e a sua política neoliberal implementada em larga escala. Cabe ao Brasil se relacionar de maneira pacífica, não se alinhando automaticamente às estruturas hegemônicas de poder, no dizer de Samuel Pinheiro Guimarães, e buscar um papel protagônico no plano regional sem abandonar o multilateralismo e o "ecumenismo antropológico" que se caracteriza como princípio norteador de sua ação. Para o caso dos vizinhos do continente, a manutenção de uma postura autônoma e firme em relação às pretensões 
estadunidenses com a Alca, deve ser mantida, pensando na igualdade e no bem-estar de todos. Para Rego, este é um embate fundamental para a existência e desenvolvimento do Mercosul. A primazia deve estar no relacionamento com a América do Sul, em particular com a Argentina, e apostar na cooperação sem descuidar de fóruns mais amplos de decisão. Notamos ser interessante perceber que a perspectiva apresentada pelo autor destaca a proeminência brasileira no sub-continente, dado o seu "espírito agregador", perseguindo a via da integração com os vizinhos, iniciada com Simon Bolívar, e visa ser atualizada, por alguns, ao longo da História, como no caso da Associação Latino-Americana de Livre Comércio (ALALC) e a Associação Latino-Americana de Integração (ALADI), Grupo do Rio (G-RIO) Comunidade Andina de Nações (CAN) e a Organização do Tratado da Amazônia (OTCA), além do processo que culminou com o Mercosul. A integração em si possui fatores positivos (as reuniões de cúpulas, a aproximação Comunidade Andina / Mercosul, as políticas de infra-estrutura energética) e negativos (as tensões sobre contenciosos territoriais, os impedimentos geográficos para a integração física - como a Amazônia e a Cordilheira dos Andes, os ilícitos internacionais - como o narcotráfico e a guerrilha, e a postura dos EUA sobre a ALCA) Assim, o Brasil não deve ser hegemônico, mas sim manter uma postura ao mesmo tempo generosa e pragmática, tendo um comportamento pivotal no sub-continente, que venha a ser capaz de criar um núcleo de poder regional.

Por fim, os temas da integração e a cooperação regional foram também contemplados pela referida pesquisa feita na EGN para os cursos de altos estudos militares. Destaca-se o orgulho dos oficiais em serem brasileiros, principalmente pelo potencial físico de desenvolvimento, seguido pela unidade nacional e pelas características do nosso povo. Até mesmo a gestão governamental a partir de 2003, recebeu uma avaliação positiva, com a busca pelo aumento do prestígio internacional do Brasil, tido como o principal fator de algum sucesso, sobretudo no caso do Mercosul, segundo a própria constatação dos pesquisadores (GRUPO ALFA, 2004). Isso foi visto como o meio de conter a influência dos organismos financeiros internacionais, dos grandes bancos estrangeiros e até da mídia sobre os destinos políticos do país. Por isso, o país deveria dar mais prioridade ainda ao Mercosul para contrabalançar a influência dos EUA, considerada problemática por causa da Alca.

Para os mesmos oficiais, no campo militar a cooperação internacional regional poderia ser incrementada no campo de C\&T e nas ações contra o narcotráfico e o contrabando nas fronteiras internacionais. Mas, a probabilidade de empreender um pacto militar com os países do Mercosul nesta década é algo improvável, ainda que muito desejável para a maioria dos oficiais. Constatamos que, segundo alguns oficiais que estudaram na Argentina, como o capitão-de-fragata Darwin Magnus Leite (2005), o passado de disputas e antagonismos foi superado pela criação do Mercosul, aproximando os interesses comuns entre o Brasil e a Argentina, com um comprometimento político 
que visa contrabalançar o poderio dos outros blocos e fóruns mundiais. Para ele, a solidez do Mercosul é grande, indo além das dificuldades atuais e estimulando a negociação com nossos concorrentes fora do bloco. A cooperação entre a ARA e a MB através dos reparos navais, das operações conjuntas e dos intercâmbios nas escolas de estado-maior são importantes para o estímulo e a consolidação entre os dois países. O intercâmbio traz vantagens para a MB através do relacionamento interpessoal, a comparação entre os currículos escolares e a criação de referências comuns (para além da herança dos EUA), do fortalecimento das medidas de confiança mútua entre os países e da ampliação dos horizontes culturais dos seus membros, ajudando a desmistificar os preconceitos. Não há uma criação de doutrina, mas apenas as distintas orientações políticoestratégicas dos governos em voga. Mesmo assim, o debate sobre defesa é superficial no Brasil. Porém, um grande problema é a restrição dos recursos orçamentários que atrapalha o desenvolvimento dessa cooperação. A resolução deste obstáculo tem a ver com a vontade política dos governos envolvidos. No tocante ao fortalecimento desta cooperação, a participação dos civis é importante no que se refere à compreensão da realidade atual e na administração dos interesses nacionais. Neste aspecto existe a opinião de alguns que acham que a pequena aproximação entre militares e civis no Brasil deve avançar para patamares mais satisfatórios, do mesmo modo que deve haver maior envolvimento do Executivo e do Legislativo neste processo.

Ainda no seio da MB, tivemos a oportunidade de conferir esta percepção com oficiaisgenerais de maior antiguidade e responsabilidade na história da corporação. Numa perspectiva que enfoca os interesses distintos entre o Brasil e a Argentina, que podem agir como complicadores da união regional, o ex-ministro da Marinha, almirante-de-esquadra Mário C. Flores (2004) avaliou as suas possibilidades e riscos, sem cair num determinismo de que a situação atual de crise econômica e divergências impossibilite a sua realização. Depois de fazer uma abordagem histórica sobre as rivalidades desde a colonização luso-espanhola e das semelhanças e diferenças das políticas econômicas e da diplomacia, aplicadas ao longo do século XX segundo a determinação dos países da Europa e EUA, Flores lembra a aproximação desses países a partir da superação da questão Coupus-Itaipu, momento em que as nações passaram a ter uma convivência cordial, o apoio brasileiro à crise das Malvinas, a redemocratização e a propensão governamental para a cooperação em que pesem o ufanismo brasileiro e as desarmonias internas argentinas. Como disse o almirante: "não está assegurada a continuidade da parceria cooperativa iniciada nos 1980 e consagrada pelo tratado de 1991”, mas ela pode frutificar caso Brasil e Argentina tomem determinado rumo no tocante à maior harmonização de interesses com decisões políticas importantes. Isto porque, para Flores, o Brasil vê no Mercosul um meio de afirmação e projeção de si mesmo no cenário internacional e uma valorização de um ideário “(neo) terceiro-mundista”, enquanto que a Argentina 
visualiza, de maneira mais concreta, o "acesso ao mercado brasileiro". Por isso, na perspectiva brasileira é importante tomar medidas para superar a questão das cotas comerciais e os reclamos empresariais, partindo para uma postura mais política de viabilização da relação com seus vizinhos que por sua vez, carecem de maior modernização da infra-estrutura econômica para a produção. Mais um ponto importante é a consideração sobre os parceiros extra-continentais na Ásia, além da questão da Alca, que possui características atraentes, mas pode implementar uma relação com os EUA de cunho neocolonial.

Quanto às possibilidades de um tipo de acordo de segurança regional, a ausência de ameaça comum dificulta a sua construção, em que pese o fato do TIAR se encontrar agonizante. Mas os países da região podem aprofundar seu ritmo de acordos específicos relacionados aos armamentos e à tecnologia de defesa. Isto ajuda a manter o grau de cordialidade e entendimento, que, para Flores, sempre foi mais fácil na área militar que na área civil. Por isso, é importante para ele que, em primeiro lugar, haja o desenvolvimento de projetos tecnológicos (informática, biotecnologia, energia alternativa e nuclear, meio ambiente, transporte, comunicações indústria bélica e tecnologia espacial). Em segundo lugar, deverá haver uma compatibilização das macropolíticas regionais e das legislações econômica e trabalhista, agropecuária e ambiental. Em terceiro lugar, é necessário ter a promoção de uma integração econômica mais consistente nos termos de comércio mundial. Por fim, deverá ter um maior aprofundamento da integração cultural, na produção artística, midiática e turística. Com isso, o único espaço no qual devem permanecer as rivalidades entre os países é o das disputas futebolísticas, tradicionais no relacionamento entre os dois países.

De volta ao tema da integração regional pela via militar, para esse almirante, havia alguns problemas internos a serem tratados pelo poder político, consoante à revisão da PDN de 1996 e à inexistência de ameaças comuns. Quanto à PDN, o almirante afirmou que "temos uma Política de Defesa vaga e frágil como orientação política de alto nível, há anos sendo revista, mas aparentemente a revisão está encalhada no M.D. Assim, o país ainda carece de maior participação dos civis na definição político-estratégica nacional. Caso os civis não o façam, as FFAA o farão, com todas as suas idiossincrasias, dada a sua tradição autônoma e corporativa. No processo de integração estratégico-militar, para esse almirante temos

apenas de definição da política, que suponho não existir, mas não tenho certeza. $O$ papel político é necessariamente geral; a questão militar está embutida nesse âmbito geral e hoje ela é realmente secundária, já que não existem ameaças que justifiquem ênfase de associação estratégica (FLORES, 2003).

Outra opinião que demonstra uma posição semelhante sobre o tema é a do almirante-deesquadra e ex-ministro da Marinha, Mauro C. Pereira (2005) que atinou para o fato de que a posição 
militar da Argentina em relação ao Brasil mudou depois da Guerra das Malvinas, o que foi mais lentamente obtido no campo diplomático. Contudo, tais mudanças têm se consolidado, apesar da época conturbada na administração Menem, pois o atual governo argentino (Kirchner) também considera o Mercosul uma "aliança estratégica". Como é sabido, as operações FRATERNO são realizadas com sucesso desde 1978 e as operações ARAEX, ocorrem desde os anos 90, sem paralelo no mundo, além das ações de manutenção e reparo de embarcações e do treinamento de pilotos navais. Em sua avaliação, as duas Marinhas realizam um bom trabalho conjunto para o cumprimento de suas responsabilidades no Atlântico Sul, apesar das sérias restrições orçamentárias impostas pelo poder civil.

O vice-almirante Fernando Diegues (2005), ex-diretor da EGN, concordou com os demais colegas de farda quanto à importância da aproximação entre o Brasil e a Argentina, lembrando as operações navais conjuntas, o intercâmbio entre as escolas de estado-maior. Nisso merece destaque o trabalho da Diretoria de Hidrografia e Navegação (DHN) na Comissão Oceanográfica Intergovernamental e na Organização Metereológica Mundial contribuindo com a presença desses países na Antártida. Por isso, as perspectivas são promissoras para a integração e a cooperação mútua. O grande problema para ambas as marinhas seria a enorme escassez de recursos imposta pelas restrições orçamentárias nacionais. No plano diplomático, é natural que o relacionamento com os argentinos passe por alguns "momentos difíceis", como a adoção das medidas protecionistas argentinas feitas por Nestor Kirchner, ou a postulação brasileira em ocupar uma vaga no Conselho de Segurança da ONU, e os problemas de posição quanto à criação da Alca, ou mesmo a postura do Uruguai de criar um acordo bilateral com os EUA. Mas, a vontade política e a responsabilidade de liderar o Mercosul devem prevalecer em nome da cooperação regional. O Executivo e o Legislativo têm um papel importante na consolidação do Mercosul, não só no plano econômico como também cultural e político. Para tal, a sociedade civil poderia também contribuir aumentando o seu conhecimento e seu interesse pelos assuntos de segurança e defesa.

Em outro depoimento, o vice-almirante Armando Vidigal (2005) notou que houve nas últimas décadas algumas variações no relacionamento entre o Brasil e a Argentina, depois da eliminação das suspeitas na área diplomática e militar. Ele ressaltou que, na área militar-naval, foram feitos três seminários com a participação de militares, civis (jornalistas, acadêmicos, políticos etc), e tiveram bastante eficácia e eficiência. Os temas abordados foram tratados de forma independente pelos dois países e depois de forma bilateral em Buenos Aires e em São Paulo. Nesse caso, eles não eram um “conchavo militar", mas uma decisão política que abarcava a participação de outros segmentos nacionais. O clima de sinceridade foi mantido, a ponto dos brasileiros criticarem a arrogância cultural dos argentinos e estes, criticarem o imperialismo brasileiro na região, o que contribuiu para 
a criação de uma relação de confiança mútua. Mais tarde, Uruguai e Paraguai pediram para participar, o que transformou o evento num arranjo mais complexo, sem o mesmo efeito dos realizados anteriormente. Para Vidigal, na nossa história, esse fato terá uma grande importância, assim, seria importante que fosse estudado, por causa da sua contribuição para a diminuição das tensões existentes na época. Isso possibilitou também que os brasileiros conhecessem mais a situação Argentina, como no caso das Malvinas, corrigindo distorções de informação e fazendo com que os argentinos soubessem que não são uma “jangada de pedra desgarrada da Europa”, mas fazem parte da América do Sul, tanto quanto os brasileiros, de quem receberam apoio e passaram a manter maior intercâmbio, com as operações FRATERNO e outras formas de atuação (reparos de submarinos e fragatas, além de treinamento de pilotos navais).

Para Vidigal, hoje em dia há uma pequena diminuição da relação entre nós e os argentinos por causa das dificuldades do Mercosul, refletindo sobre a área militar ao diminuir algum interesse comum. Mas, a aproximação pode ser feita através da indústria militar, pois ambos os países possuem enorme dependência no setor dos países ricos, principalmente depois da Revolução nos Assuntos Militares (RAM), como podemos ver na Guerra do Iraque. Um tipo de cooperação regional poderia levar a uma "interdependência estratégica" na produção de armamentos em larga escala para atender à região e a construção de um navio-patrulha com projeto comum e capacidade de ser adaptado para as necessidades de cada país, assim como, poderia sofrer pequenas modificações para funcionar enquanto um navio de pesquisa oceanográfica na Zona Econômica Exclusiva (ZEE) e nas águas internacionais e poderia servir também aos africanos.

Outra maneira de cooperação apresentada por esse oficial foi a presença brasileira na Antártida, que teve a sua "descoberta" feita pelo ex-ministro Maximiliano da Fonseca, há décadas e ajudou o Brasil a ser membro pleno do Tratado de Washington. Isto nos uniu mais ainda ao Chile e à Argentina, apesar das divergências, quanto às pretensões territorialistas desses dois países vizinhos. O continente tem muito valor estratégico por causa da importância do seu clima sobre esses países e das passagens transoceânicas, assim como ajuda a consolidar sua presença na Zona de Paz e Cooperação da América do Sul (ZPCAS), contribuindo para as medidas de confiança prosperarem entre eles.

Por isso, segundo Vidigal, não seria necessário ter uma doutrina prévia para empreender a cooperação, mas sim planos de ação com objetivos e resultados, vide o exemplo da Grã-Bretanha e seu expansionismo, só depois corroborado e explicado segundo a interpretação de Mahan (1935). A doutrina será construída com o tempo para justificar as relações bilaterais entre o Brasil e a Argentina. Cada país tem as suas peculiaridades, mas, nós podemos caminhar para a maior proximidade com a Argentina, ainda que ela tenha uma estrutura de segurança e defesa distinta do 
Brasil, com a atribuição de uma guarda costeira (a Prefeitura Naval), distinta da ARA. Neste sentido, as propostas de junção de ambas, como queria o ministro Jaunauarena, foram consideradas positivas. Só os EUA têm necessidade e condições de manter a Guarda Costeira e a Marinha em separado. No caso do Brasil, as atribuições semelhantes à Guarda Costeira (o ex-ministro e almirante-de-esquadra Maximiliano da Fonseca era a favor da existência dessa corporação) podem ser dadas à Polícia Federal, desde que esta corporação seja dotada de recursos e treinamento. Assim como a fiscalização da navegação costeira e ribeirinha pode ser dada aos governos locais e estaduais, deixando com a MB apenas a normatização da segurança a bordo e do treinamento dos marinheiros civis. Isso inclui tanto os balseiros das lagoas da Baixada de Jacarepaguá, na Zona Oeste da cidade do Rio de Janeiro, como a navegação na Bacia Amazônica, passando por toda a navegação pesqueira artesanal do litoral e pela hidrovia Tietê-Paraná. Ao seu ver, a MB deve estar engajada na defesa e exploração da Amazônia Azul, como Força Naval e Autoridade Marítima, atendendo aos interesses nacionais.

Uma outra opinião que segue o curso geral de aprovação das iniciativas de cooperação regional foi a do comandante das forças navais de superfície da MB, o contra-almirante Antônio Nigro. Para ele, a cooperação e a competição têm sido a tônica de ambos os países, de acordo com a época, mas isso tende a um equilíbrio. No plano econômico, o Mercosul foi importante para neutralizar a Alca. No plano político, existiu integração do subcontinente, mas ainda carece de uma estratégia que o implemente de modo mais efetivo. No plano político-militar, entende-se que os exercícios e operações navais conjuntas têm sido um bom exemplo de convivência, como as realizadas entre Brasil e Argentina, além da operação UNITAS, que contam com a participação de outras Marinhas do continente e a Armada espanhola. Isto sem falar no apoio regional que pode ser intensificado no combate aos ilícitos internacionais. Nigro ressaltou ainda a participação de dez guardas-marinha argentinos no navio-escola Brasil, na viagem de instrução do ano de 2005 como uma medida de confiança mútua entre os dois países.

No caso da Argentina, no interior da ARA, uma abordagem genérica sobre a região e a questão da situação internacional, foi feita pelo contra-almirante Carlos Frasch (2002) considerando o momento histórico de transformações profundas no cenário mundial numa crise de paradigmas, com as reflexões presentes nas obras de Huntington, Fukuyama, Ortega Y Gasset e Vargas Llosa com intuito de inserir as características culturais de nossa realidade (que vive num ambiente de defasagem tecnológica e enfrenta profundos problemas sociais), o debate entre pensadores modernos e pós-modernos sobre a globalização e nos fatos marcantes da atualidade, sobretudo no ocorrido pós-11 de setembro. Assim, da ameaça do terror nuclear passamos ao terrorismo do ciberespaço. A Argentina, por sua vez foi afetada pela situação, que em termos nacionais ainda 
trabalha com uma percepção ideológica sobre defesa decorrente de conflitos nacionais do passado, o que compromete a sua racionalidade e a eficiência. $\mathrm{O}$ autor foi da posição de que nós latinoamericanos sequer entramos plenamente na modernidade, haja vista a sua situação de corrupção, desigualdade social e inoperância. Para ele isto põe dúvidas sobre a percepção dos pós-modernos sobre a globalização como sendo um significado de mudança de paradigma, conforme o faz também Habermas (2000). Ressaltamos que, no texto de Frasch, há toda uma reflexão sobre a situação global, no qual entram os temas sobre as cidades, a governância, os inimigos da globalização, o terrorismo, o narcotráfico, a disputa entre a possibilidade de uma utopia ou uma heterotopia global. No intuito de focar apenas na questão regional, podemos perceber que o autor considera os aspectos problemáticos da relação Alca x Mercosul, a ação dos organismos internacionais no que se refere à questão sócio-econômica (como os bancos e o FMI) e as novas ameaças no subcontinente, como a interferência dos EUA com o Plano Colômbia, além do poder da mídia e o seu papel social.Tal contexto interferiu no redesenho das FFAA, seu preparo, emprego e missão, pois a percepção do inimigo e as situações de crise estão cada vez mais complexas. Por isso, para enfrentar os desafios mundiais, se faz mister que a América Latina deixe de ser entendida como uma colônia e possa se constituir num só grupo diante da comunidade internacional a fim de ser ouvida e ajudar a tomar as decisões sobre a realidade em que vivemos.

Sobre o mesmo tema, temos uma reflexão feita pelo capitão de fragata Julio Graff (2000), publicada na Revista da Escuela de Guerra Naval Argentina (ESGN), onde a problemática da Nova Ordem Internacional é posta juntamente com o processo de globalização e a unipolaridade em termos militares, com o predomínio dos EUA. Neste artigo há toda uma série de questões decorrentes desta nova configuração para os países que são sobejamente tratados por vários analistas, configurando o que se conhece por "senso comum acadêmico", tais como: o questionamento do alcance e soberania do Estado-nação, a formação de Forças de composição transnacional, o ressurgimento de conflitos étnicos e religiosos, a revisão da situação da ONU, o ressurgimento de nacionalismos sufocados por décadas, a influência dos meios de comunicação etc. Decerto que há várias implicações para os países em função de suas características e histórias próprias. Para a realidade Argentina, Graff destacou a consolidação da democracia, o alinhamento com os EUA, o apoio argentino à Guerra do Golfo, a formação do Mercosul, a resolução de problemas limítrofes, a aparição de ameaças como o terrorismo e o narcotráfico, além da questão ecológica e da redução dos mercados tradicionalmente constituídos em nome da competitividade e da eficiência.

Dentro desse contexto as relações estabelecidas entre a Argentina e o Brasil merecem destaque com as suas "divergências" e "convergências" históricas. Com a criação do Mercosul, os 
temas militares, que já vinham se desenvolvendo anteriormente a partir dos anos 60, tomaram um impulso maior em termos da cooperação. Para Graff, houve novamente o pioneirismo das Marinhas do subcontinente nesse processo, o que pode vir a fortalecer o ideário de um tipo de "segurança cooperativa" na coletividade regional. Os fatores deste tipo de segurança devem ser observados, tais como: a) a soma das forças nacionais regionais deve ser superior à coalizão agressora, b) as nações reunidas devem ter a mesma noção de segurança e c) as nações envolvidas devem subordinar legítimos interesses políticos próprios ao bem comum. O problema é saber se um esquema de segurança coletiva não resultará numa situação exatamente oposta daquela que se pretende ao formá-lo, em função de inevitáveis conflitos, tal como preconizava Morghenthau. Deste modo, há prós e contras que devem ser considerados, tanto de cunho idealista quanto realista. Uma "doutrina de segurança cooperativa" poderia ser estabelecida, levando-se em conta: a identificação de ameaças comuns tem um consentimento institucionalizado que visa a colaboração, ao invés do emprego conflituoso da força e, por último, a defesa do próprio território é o único objetivo militar legítimo, por sua vez subordinado ao consenso internacional. Esta configuração de segurança exige ainda que haja padrões comuns de técnicas e operações entre as forças nacionais no treinamento e na adoção de MCM. Segundo Graff, há várias questões decorrentes levantadas por alguns autores, tais como a associação da segurança cooperativa com o significado de uma medicina cooperativa, e o risco de ceticismo quanto à renúncia de poder dos Estados, e a necessidade de ideia de que o enfoque tradicional de segurança nacional para a redução de incertezas e desconfianças (exercícios militares e regulação da capacidade bélica) é incompatível com a necessidade de pensar os seus custos e a sua eficiência a fim de criar condições para as características necessárias de segurança cooperativa, tais como: regulação ofensiva, configuração defensiva, transparência mútua e integração funcional.

A realidade dos países do Mercosul foi abordada por aquele autor nos termos do aumento da interdependência regional e da problematização da possibilidade de criar uma aliança estratégicomilitar dadas as circunstâncias dos países envolvidos, a saber: baixo valor estratégico do subcontinente no cenário internacional, distintas percepções da realidade e do tratamento do tema de segurança e defesa, diferentes abordagens em termos de política externa, necessidades internas nacionais urgentes que limitam os recursos com segurança e defesa, e uma postura militar que prioriza pouco a necessidade de cooperação, configurando um " autismo", além de seus distintos graus de autonomia, inclusive em relação ao orçamento estabelecido pelos civis. As próprias relações civis-militares possuem aspectos próprios na redemocratização regional do final do século passado. Isso se traduz em estrutura de forças e missão constitucional variada, como ocorre no caso de Argentina e Brasil, Paraguai e Uruguai. Esses países têm perseguido seus objetivos de 
organização preparo e emprego militar visando a modernização de seus recursos e fazendo esforços de capacidade de resposta à situação de ameaças hodiernas, de cunho militar e não-militar, novas e tradicionais, impondo às FFAA novas atribuições.

Não obstante é necessário levar em consideração a aproximação Brasil-Argentina, depois da superação de divergências na Bacia do Prata e da criação do Mercosul. Tais países andaram um caminho bastante propício para superar suas divergências. Graff parece ter a postura de um certo otimismo regulado, que está baseado em algumas de suas reflexões. Primeiro - as capacidades individuais não são suficientes para superar as ameaças existentes. Segundo - fortalecer os mecanismos regionais beneficia também a cada país. Terceiro - a integração não quer dizer homogeneidade, mas o reconhecimento de questões comuns. Embora o Mercosul em sua criação não explicite o surgimento de um mecanismo de defesa regional, isso não impede que algumas oportunidades sejam aproveitadas, sem que precisemos passar por uma situação historicamente belicosa com a Europa. No caso das Marinhas as medidas tomadas entre os dois países foram benéficas, como a postura de Brasil e Argentina diante do TNP e de Tlatelolco os acordos de cooperação na área nuclear e as visita dos presidentes às instalações dessa tecnologia, como as visitas a Aramar e a Pilcaniyeu; os acordos sobre armas químicas e biológicas com a participação do Chile, o regime de controle de mísseis, as reuniões de ministros da defesa e o treinamento da aviação naval. Neste sentido, parece a esse oficial que há "cooperação" suficiente e positiva, mas não existe "integração" que aponte para uma segurança cooperativa, o que pode vir a ocorrer no futuro, como um desdobramento do esforço mercosulino.

A partir daí poderá considerado um conjunto de problemas culturas, políticos e militares e desenvolver um processo de integração nas áreas de conhecimento e tecnologia, recursos para a defesa e um conjunto de ações complementares a fim de prever conflitos, aumentar as MCM, criar instrumentos de consenso, superar desafios econômicos e complementação político-militar a fim de aprender entre si e criar interesses comuns.

Uma opinião semelhante na ARA é a do contra-almirante José M. Maurizio (2003), que descreveu a importância da compreensão da realidade de maneira a perceber as novas ameaças e seus impactos no aproveitamento dos recursos humanos e materiais das FFAA argentinas. Dentre vários aspectos o ambiente internacional favorece a cooperação estratégica na América do Sul, como um dentre vários exemplos de se ter uma "visão participativa e abrangente" que torne mais eficazes e eficientes as respostas frente ao clima das possíveis instabilidades. A região tem importância que não pode ser ignorada, portanto, ser válido a manutenção do incentivo à cooperação internacional. 
Houve também, no âmbito da ARA, uma outra análise da valorização da concepção estratégica de segurança cooperativa regional, nos marcos da integração entre Brasil e Argentina, que pode fazer frente ao contexto das novas ameaças e aumentar a interoperabilidade e o entendimento entre as suas Marinhas, feita pelo capitão Del Pozzi (2003). Sem considerar também que se possa perder a autonomia nacional, esses dois países podem utilizar o Mercosul como um grande motivador para continuar avançando nas medidas de confiança mútua, nos acordos bilaterais e nas operações navais. Mais uma vez as operações FRATERNO foram dignas de nota, tendo apenas o lamento do autor sobre a falta de recursos que a interrompeu em 1995, 1996 e 2001. De igual modo, as operações ARAEX são valorizadas pela sua singularidade no atendimento das necessidades de aprestamento das duas Marinhas. Não se deve esquecer, todavia, das operações ATLASUR, feitas por argentinos e sul-africanos em conjunto com brasileiros e uruguaios. Elas aumentaram o leque de participantes e o intercâmbio das forças navais. Del Pozzi destaca também as operações ACRUX, feitas na hidrovia Paraguai-Paraná com o Brasil, Argentina, Paraguai Uruguai e Bolívia que realiza operações navais, sem se imiscuírem no combate ao terrorismo e ao narcotráfico, por serem estas atribuições policiais. Este oficial faz coro com os que defendem a postura adotada pela MB e pela ARA o que contribui para buscar soluções regionais na atual configuração mundial, aumenta a confiança mútua, a cooperação e a integração e estimula o desenvolvimento de uma segurança cooperativa, resultando na possibilidade futura na criação de uma Força de Tarefas Combinadas para a segurança e a defesa do mar do subcontinente.

\section{Considerações Finais}

Abordamos aqui nossos comentários sobre o discurso dos militares acerca da cooperação regional. Entendemos que o pensamento dos oficiais da ARA e da MB demonstra que se deve ter atenção aos rumos sobre a consolidação do Mercosul e seu desenvolvimento como um mecanismo chave de aumento da cooperação entre os países, não somente no plano econômico, mas também no plano cultural e político. Parece-lhes que as dificuldades não constituem motivo para retardar o incremento das vinculações em outros campos. Nota-se que a sua existência é posterior às medidas tomadas no campo político-militar entre o Brasil e a Argentina. Com a sua fundação, as possibilidades de entendimento tendem a crescer, haja vista o exemplo mantido no nível satisfatório, de entrosamento mantido nas últimas décadas, inclusive no campo militar-naval no patrulhamento do mar, no treinamento de recursos humanos e nas MCM tomadas para a manutenção do equilíbrio da ZPCAS.

Contudo, pensamos que os esforços de maior intensidade na cooperação permanecem aí, não evoluindo para uma entidade coletiva de defesa regional. Pensamos que há espaço para incrementar 
mais ações envolventes das FFAA de Brasil e Argentina a partir do contexto de maior aproximação entre ambos iniciado no passado. Embora a chamada Nova Ordem Internacional (NOI) tenha trazido questionamentos sobre os fundamentos do Estado-nação e a existência das novas ameaças contribuam para aumentar o clima de preocupação e instabilidade, decerto a inexistência de uma ameaça efetiva no campo da segurança internacional impede a realização de tal possibilidade. Sobre a avaliação de uma entidade regional, as novas ameaças e o atentado terrorista de 11 de setembro não sensibilizaram os países da região a empreender este tipo de associação. Até porque, isto também dependeria do posicionamento dos EUA. Este país já tem ingerências diretas e crescentes no subcontinente através da Colômbia. Tal fato causou alguma apreensão nos países do norte da América do Sul, notadamente da região amazônica e isto, portanto, não tem diretamente a participação da Argentina. Assim, a formação de uma entidade como uma Organização do Tratado do Atlântico Sul (OTAS), pareceu não ter sentido em função: a) das diferenças marcantes entre os países que a poderiam compor; b) da ausência de uma aliança estratégica inimiga que ameace o subcontinente; c) da presença hegemônica dos EUA, para quem não interessa uma entidade desse tipo no momento atual, pois para este país já basta a existência de seu Comando Militar Sul, para garantir a segurança hemisférica.

Mais um aspecto é como as prioridades brasileiras, segundo a PDN até então, estavam centradas na Amazônia, parecia não fazer tanto sentido que se desenvolvesse uma entidade de defesa com a Argentina. Em outras áreas de projeção do poder nacional como no Atlântico Sul o equilíbrio tem sido bem maior e não merece atualmente o qualificativo de zona de risco ou de incertezas. Por esta razão, os projetos em andamento e os propostos para aumento da confiança e da cooperação parecem ser suficientes atualmente e num futuro próximo. Do nosso ponto de vista, por mais que haja uma crescente interdependência entre o Brasil e a Argentina, tal fenômeno não evoluiu sequer para a configuração de uma doutrina que paute a segurança e a cooperação regional, quanto mais o que venha a levar à integração. Percebemos que o significado dessa doutrina é diferenciado entre tais países, pois o Brasil fica a meio caminho de rever a sua PDN para contemplar algumas transformações recentes no cenário mundial e a sua declaração de intenções constitucionais sobre a integração regional, mas a Argentina se mostrou bem mais explícita nas suas intenções. Apenas a padronização de alguns procedimentos (legislação, administração de recursos materiais e humanos) para tal fim no campo da defesa já é visto no Brasil como algo suficiente. Isto ocorre tanto por causa da interpretação de que o país saia perdendo, por causa de alguns costumes e práticas historicamente arraigados ou por causa da desconfiança de que haja alguma ingerência dos EUA ainda que de maneira indireta, na configuração da estrutura de forças para os países da região. Pensamos que tal fato pode ser relacionado ainda às atividades de natureza especificamente 
voltadas para a formação profissional-militar no grau de autonomia desses países em relação aos EUA, no que diz respeito às doutrinas de preparo e emprego, quanto na autonomia institucional em relação ao Estado e à sociedade, na formatação do modelo de educação profissional que Brasil e Argentina possuem como menor ou maior vinculação ao sistema de ensino nacional. Neste caso seria válido discutir ainda até que ponto as FFAA estariam preparadas para empreender efetivamente tarefas voltadas para a defesa regional, quando elas apresentam deficiências relacionadas à defesa nacional. Por isso é importante avaliar até que ponto tal situação não poderia representar muito mais um somatório de problemas do que uma composição satisfatória para as necessidades da comunidade de países da região. Entendemos que as próprias experiências de maior intercâmbio profissional entre a MB e a ARA são importantes para estabelecer continuamente um diálogo que vise o aproveitamento mútuo de potencialidades e capacidades a fim de compatibilizar procedimentos nos quais, na hipótese de uma experiência futura, haja mais do que a fraternidade atual, familiaridade sobre o conjunto de questões e ações que envolvam o preparo e o emprego militar, onde a modelagem de um determinado tipo de formação educacional pode dar uma singular e efetiva contribuição.

\section{Referências Bibliográficas}

BARNABÉ. I. R O Mercosul e a Integração Regional. Tese de doutorado, IFCH, UNICAMP, 2003.

DEL POZZI, H. Una Visión de las Operaciones Navales Combinadas de Argentina Y Brasil y su Contribuición a la Seguridad Cooperativa Regional. Seminário REDES 2003 CHDS/NDU, Santiago do Chile, out. 2003.

FLORES, M. C. Possibilidades e Riscos da União Regional. Texto apresentado no Seminário IEPES / UBA. Rio de Janeiro, dez. 2004.

. Reflexões Estratégicas: repensando a defesa nacional, Texto de Trabalho, 2003.

. Uma Estratégia para o Brasil, Texto apresentado no Ciclo de Debates do Ministério da Defesa, em Petrópolis em 2003. Disponível em

$<$ <www.defesa.gov.br/ciclodebates/almtemariocesarflor.htm>>. Acesso em 04/9/2003.

FRASCH, C. A. Latinoamérica Global. Buenos Aires: Instituto de Publicaciones Navales, 2002.

FRAGA, R. La Custion Militar al Finalizar Los 90. Buenos Aires: Editorial Centro de Estúdios Unión para la Nueva Maioría, 1997.

GRAFF, J. La Seguridad Cooperativa en el Mercosur, Revisa de la Escuela de Guerra, No 50, julio de 2000. p.117-165. 
GRUPO ALFA, Pesquisa apresentada como trabalho final da disciplina de Ciência Política, do MBA COPPEAD-EGN 2004.

HABERMAS, J. La Constelación Posnacional. Barcelona: Paidós, 2000.

HAYES, Margareth, D. Future Naval Cooperation with Latin America: Discriptions and Assesment, Center For Naval Analisis, Alexandria, 1995.

KEOHANE, R. Soberania Estatal e instituições multilaterais: respostas à interdependência assimétrica "in"Ministerio de Defensa - Estado Maior Conjunto de las Fuerzas Armadas. Estudio Comparado de Las Políticas de Defensa. Buenos Aires: Centro de Estudios Estratégicos, 2003, p 247-248.

MAHAN, A, T. Influência del Poder Naval en la Historia (1660-1783). Buenos Aires: Escuela de Guerra Naval, 1935.

MAURIZIO, J. M. Algunos aspectos a Considerar para Elaborar Políticas de Defensa, Seminário REDES, 2003, CHDS / NDU, Santiago do Chile, out. 2003.

MIYAMOTO, S. Geopolítica do Brasil; algumas considerações. In: CARVALHO, L. A. Geopolítica e Relações Internacionais. Curitiba: Juruá, 2003, p. 183-228.

. Mercosul: e Atlântico Sul: das divergências ao entendimento. História, São Paulo, v. 16 1997, UNESP. p. 49- 67.

MOISÉS, J. A . O Futuro do Brasil: a América Latina e o fim da guerra fria. Rio de Janeiro: Paz e Terra/ São Paulo: EDUSP, 1992.

NYE, J. Bound to Lead: the changing nature of american power. New York: Basic Books, 1990.

REGO, J.A.B. Elementos para uma Geopolítica Brasileira no Século XXI. EGN, 2003.

ROTH,L. C. As Medidas de Confiança Mútua e Suas Perspectivas para a MB e as Armadas da Argentina e do Chile. EGN, 2002.

RUSSELL, R.; TOKATLIAN, J.G. Argentina, Brasil y EEUU: El desafio de uma esfera de cooperación. Agenda Internacional, Ano 1, Número2 , 4T 2004, Buenos Aires, Fundacion Vision Desde El Sur, pg 16-24.

SAINT-PIERRE , H. L.; MATHIAS, S. Reflexões sobre o Mercosul: unidade estratégica e cooperação militar. História, São Paulo, v. 16 1997, UNESP, p. 83-108.

SILVEIRA, C. de C. A Formação Militar-Naval Brasil Argentina no Contexto de Cooperação no Atlântico Sul, GEDES-UNESP-Franca, 2005

VAZ, A.C. Cooperação, Integração e processo negociador: a construção do Mercosul. Brasília, BRI, 2002. 


\section{Entrevistas}

Entrevista com o almirante-de-esquadra Mauro César Pereira, concedida ao autor por correio eletrônico, em 31 de março de 2005.

Entrevista com o vice-almirante Fernando Diegues, concedida ao autor por correio eletrônico em 31 de março de 2005.

Entrevista com o vice-almirante Armando Vidigal, concedida ao autor em 01 de março de 2005 na cidade do Rio de Janeiro.

Entrevista com o contra-almirante Antônio Nigro, concedida ao autor por correio eletrônico em 31 de março de 2005.

Entrevista com o capitão-de-fragata Darwin Magnus Leite, concedida ao autor por correio eletrônico em 16 de maio de 2005.

Artigo recebido em 09/2010. Aprovado em 11/2010. 